\title{
Effect of the impact of rigid rods on coffee fruit detachment efficiency by mechanical vibrations
}

\author{
Ely Queiroz Gomes ${ }^{1}$ (D), Fabio Lúcio Santos ${ }^{2}$ (D), Moysés Nascimento ${ }^{3}$ (D), Nara Silveira Velloso ${ }^{4}$ (D)
}

\author{
${ }^{1}$ Universidade Federal de Uberlândia/UFU, Faculdade de Engenharia Mecânica, Uberlândia, MG, Brasil \\ ${ }^{2}$ Universidade Federal de Lavras/UFLA, Departamento de Engenharia/DEG, Lavras, MG, Brasil \\ ${ }^{3}$ Universidade Federal de Viçosa/UFV, Departamento de Estatística, Viçosa, MG, Brasil \\ ${ }^{4}$ Universidade Federal de Lavras/UFLA, Departamento de Engenharia Agrícola, Lavras, MG, Brasil \\ Contact authors: ely_qg@hotmail.com, fabio.santos@ufla.br, moysesnascim@ufv.br, naravelloso@yahoo.com.br \\ Received in April 2, 2020 and approved in June 18, 2020
}

\section{ABSTRACT}

The mechanization of field activities has been the response of coffee producers to the labor shortage, especially for fruit harvesting. The use of mechanical harvesters allows greater harvesting efficiency and ensures the economic viability of coffee plantations, which currently depend mainly on the reduction in production costs. The principle used for mechanized coffee harvesting is based on the principle of mechanical vibration. The objective of this study was to analyze the dynamic behavior of the coffee fruit-peduncle-branch system under mechanical vibration and the impact of the vibrating rods on the fruit detachment process in association with this behavior. Fragments of coffee branches containing fruits in the unripe and ripe stages were used in this experiment. These samples were subjected to different frequencies $(20,30,40$, and $50 \mathrm{~Hz})$ and amplitudes $(0.002,0.003$, and $0.004 \mathrm{~m})$. Another variable analyzed was the form of vibration transmission to the fruits, with the vibrations being transmitted to the samples with or without the impact of the fiberglass rods. The fruit detachment efficiency increased as the ripening stage progressed from unripe to ripe. A higher detachment efficiency occurred with the increase in vibration frequency and amplitude because of the higher vibrational energy imposed on the fruit. The detachment efficiency was low when the vibration was transmitted without the impact of the rods. Conversely, the vibration in combination with impact achieved a mean detachment efficiency of approximately $90 \%$

Key words: Coffee crop; dynamic behavior; harvester machine; mechanical harvesting.

\section{INTRODUCTION}

Since the nineteenth century, coffee crop has been a major agricultural activity in Brazil. Among the Brazilian states, Minas Gerais accounts for $54.1 \%$ of the country's total coffee production (Companhia Nacional de Abastecimento CONAB, 2019). Coffee crop is going through a transitional period because of the difficulty in securing labor, which makes manual harvesting impractical (Ortega; Jesus, 2011; Silva et al., 2015). The mechanization of field activities allows greater operational efficiency and ensures the economic viability of coffee plantations, which, in this scenario, depend on reduced production costs (Silva; Silva; Magalhães, 2014; Cunha et al., 2016).

When manually performed, coffee harvesting can represent up to $60 \%$ of the cost of a bag, and those costs are mainly associated with labor (Oliveira et al., 2007; Lanna; Reis, 2012). The mechanization of cultivation and harvesting operations plays an important role in supporting the coffee supply chain, providing greater peace of mind to coffee producers in times of crisis by reducing operational costs (Silva et al., 2010). Santinato et al. (2014) state that mechanized harvesting with maximum efficiency reduces operational costs and minimizes the need for manual reharvesting.

The principle used to perform mechanized coffee harvesting is based on mechanical vibrations (Coelho et al.,
2015; Ferreira Júnior et al., 2018). The options available in the market include self-propelled harvesters that perform all the steps of the harvesting process to small portable machines that are employed in a semimechanized harvesting processes, always using the principle of mechanical vibrations for fruit detachment.

The harvesting process by mechanical vibration involves the action of rods that induce vibration of the fruits and branches of the plant by impact. Thus, when vibrational energy is used to pick fruits, the association of variables such as vibration frequency and amplitude are essential for an effective process (Sessiz; Özcan, 2006; Santos et al., 2010a; Santos et al., 2010b; Coelho et al., 2016). By subjecting the coffee plant to forced vibration, the response of this system becomes complex due to its geometric and mechanical properties. Therefore, factors such as vibration frequency and amplitude and ripening stage are important and necessary to understand the behavior of the system (Ciro, 2001; Oliveira et al., 2007; Santos et al., 2010a; Santos et al., 2010b; Silva et al., 2010; Tinoco et al., 2018; Coelho et al., 2015; Santos et al., 2015; Silva et al., 2015; Coelho et al. 2016; Villibor et al., 2019).

Much of the literature on coffee harvesting by vibration has studied the effect of vibration based only on the variation of parameters such as frequency, amplitude, and ripening, without observing the influence of the impact (Ciro, 2001; Oliveira et al., 2007; Santos et al., 2010a; Santos et al., 2010b; 
Silva et al., 2010; Coelho et al., 2015; Santos et al., 2015; Silva et al., 2015), which does not reflect the real dynamics of the coffee harvesters.

Gomes et al. 2017 studied the effects of the impact of rigid rods on coffee fruits detachment efficiency. However, the authors evaluated only the interaction of a rigid rod with isolated fruits subjected to impact, this scenario does not reflect the actual conditions during coffee harvesting process by mechanical vibrations.

The knowledge of coffee plants behavior in machineplant interaction can aid on the design of new harvesting mechanisms, as well as the development of equipments already available, become them more suitable, efficiency and with lower operational cost. Thus, the objective of this study was to analyze the dynamic behavior of the coffee fruit-pedunclebranch system subjected to mechanical vibration and associate the effect of the vibrating rods on the fruit detachment process. In addition, fragments of the coffee branch were used to determine the behavior of the fruit-peduncle-branch system to ensure the harvesting conditions were close to those in the field.

\section{MATERIAL AND METHODS}

Arabica coffee samples were used in this study. The Coffea arabica variety, Catuaí Vermelho cultivar (IAC 144) was used at the unripe and ripe ripening stages.

To perform the experimental tests, the coffee fruits were subjected to different combinations of vibration frequencies and amplitudes using a Ling Dynamic Systems (LDS) vibration system powered by a PA $1000 \mathrm{~L}$ amplifier, with a $10 \mathrm{~L}$ field power supply (FPS), a V 555M6-CE electromagnetic shaker, and a Dactron Comet USB controller. In this system, the signal generator receives the commands directly from a computer using software specifically developed for this purpose by the manufacturer. The generated electrical vibration signals are sent to the amplifier, where they are amplified to power shaker. In the shaker, the electrical signals from the amplifier are converted into movement of its mobile base. The system was controlled by an accelerometer (piezoelectric acceleration transducer) manufactured by $\mathrm{PCB}$, with a working range of 10 to $4000 \mathrm{~Hz}$. The response of this accelerometer allows precise control of the frequencies and amplitudes of vibration.
A Festo hydraulic test bench was also used, which consisted of a mounting rack and accessories for the assembly of hydraulic systems and circuits. This equipment was used to promote the displacement of the fruit-peduncle-branch systems relative to the vibrating rigid rods, with constant velocity during the detachment tests by mechanical vibrations, ensuring uniformity of the tests in each repetition.

The rods used to induce vibration to samples were manufactured in fiber glass, in a cylindrical shape with 0.005 $m$ diameter. Due to the fact that samples are not homogeneous in relation to the diameter of the branch and the arrangement of the fruits, the fiber glass rigid rods were attach in a mechanism that allows changing the distance between them (Figure 1). This feature was necessary to set up the experimental apparatus to the coffee samples evaluated. Additionally, it was possible to avoid the pulling of the fruits during the translation movement. In this way, only the effect of the vibration and impact of rods on coffee samples were evaluated.

\subsection{Detachment efficiency by mechanical} vibrations with and without direct impact on the fruit-peduncle-branch system

The detachment efficiency was determined considering the ratio between the number of detached fruits and the initial number of fruits present in the branch. This ratio is given in Equation 1.

$\eta=100\left(\frac{n_{d}}{n_{i}}\right)$

where:

$\eta=$ the detachment efficiency, $\%$;

$\mathrm{n}_{\mathrm{d}}=$ the number of detached fruits; and

$\mathrm{n}_{\mathrm{i}}=$ the initial number of fruits in the sample.

Coffee branches $0.15 \mathrm{~m}$ in length were collected in the field and taken to the laboratory and prepared for the acquisition of samples (fruit-peduncle-branch system). It is desirable to employ the total length of branches to compose the samples, however, due the experimental apparatus limitations, it was possible to evaluate samples with $0.15 \mathrm{~m}$ in length.
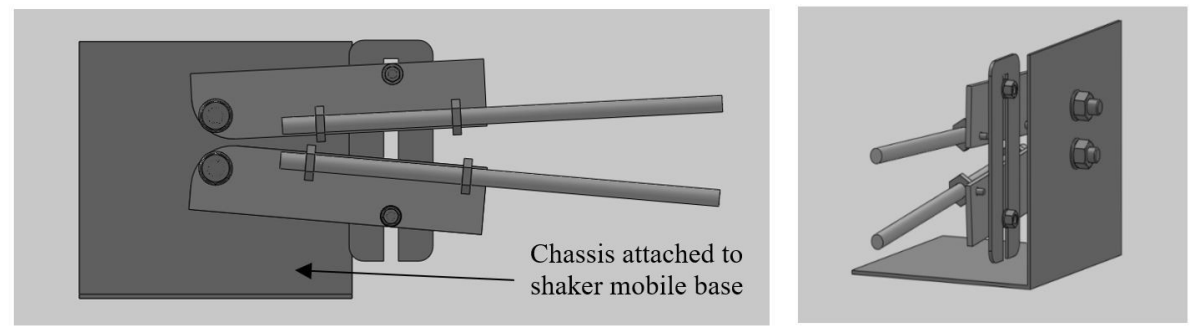

Figure 1: Mechanism to provide the correct opening of rigid rods. 
Before performing each test, the number of fruits present (samples) in the coffee branch was determined. Immediately after the test, the number of fruits was quantified again, thus enabling the determination of the detachment efficiency (Equation 1).

Based on different experimental arrangements, the coffee fruit detachment efficiency by mechanical vibrations without impact and by mechanical vibrations transmitted by the impact of rigid rods were evaluated. In the arrangement where vibration was transmitted to the samples without impact on the fruit-peduncle-branch system, the vibrational energy was transmitted from the clamping point between the tested sample and the shaker.

The test duration was set to 20 seconds. This vibration time was adopted because it corresponds to the time that a plant remains exposed to excitation when the harverster operates at a speed of $0.05 \mathrm{~m} \mathrm{~s}^{-1}$, which is the minimum speed adopted in harverters coupled to tractor (Oliveira et al., 2007). Figure 2 shows the experimental apparatus used to perform tests in this arrangement.

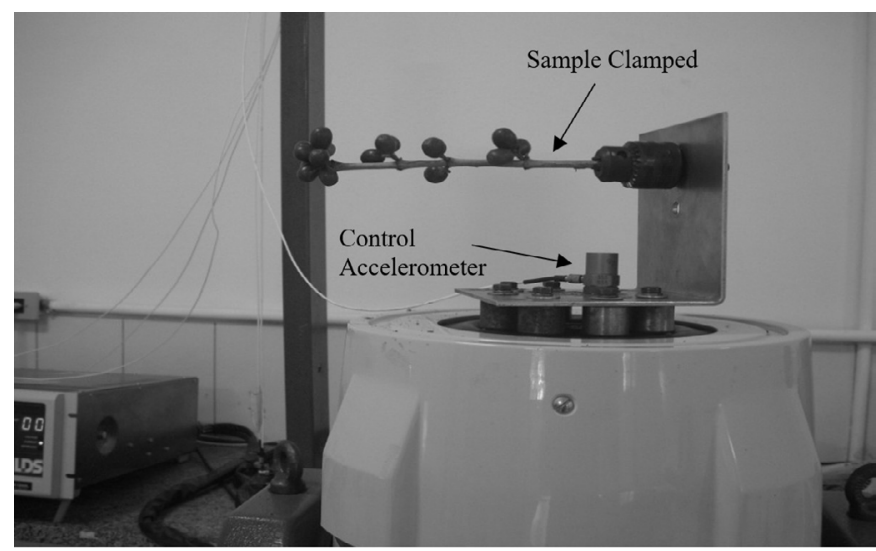

Figure 2: Sample prepared for testing coffee fruit detachment efficiency without impact.

For the experimental arrangement in which vibration was transmitted to the coffee fruit-peduncle-branch system by impact (Figure 3), the speed of displacement of the samples relative to the rods had to be controlled. Thus, the translational speed of the fruit-peduncle-branch system was set at $0.007 .5 \mathrm{~m} \mathrm{~s}^{-1}$, which was achieved and controlled by the hydraulic actuator. This value was necessary to ensure that the displacement of the sample between the vibrating rods occurred in a time interval of 20 seconds, allowing the exposure time to vibration in the two experimental arrangements to be the same.

The following factors were considered for the detachment efficiency tests: two ripening stages (unripe and ripe), four vibration frequencies $(20,30,40$, and $50 \mathrm{~Hz})$, three vibration amplitudes $(0.002,0.003$, and $0.004 \mathrm{~m})$, and two forms of vibration transmission to the samples (mechanical vibrations transmitted without a direct impact on the fruit-peduncle-branch system and vibrations transmitted directly to the fruit-pedunclebranch system by the impact of the rigid rods).

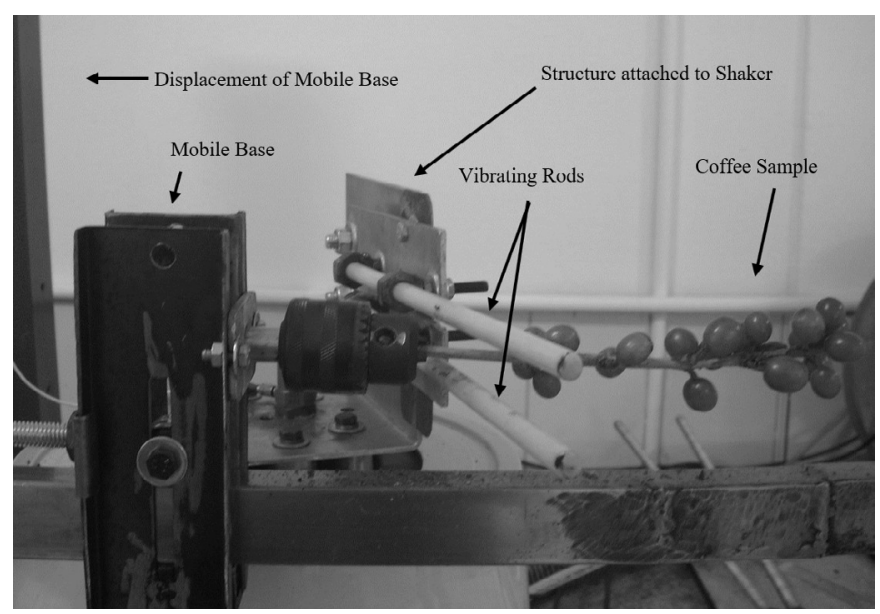

Figure 3: Sample prepared for testing detachment efficiency from the impact of the rigid rods.

\subsection{Data analysis}

The study involved the evaluation of three routines: vibrations transmitted to the fruit-peduncle-branch system by impact (Routine 1), evaluation of the effect of different forms of vibration transmission (with and without impact) on unripe fruit (Routine 2), and ripe fruit (Routine 3) on detachment efficiency.

Routine 1 had a completely randomized design, with three replicates, in a factorial arrangement, in which the following factors were considered: two ripening stages (ripe and unripe), four frequencies $(20,30,40$ and $50 \mathrm{~Hz})$ and three amplitudes $(0.002,0.003$ and $0.004 \mathrm{~m})$. In this routine the vibration was transmitted from the impact of the rigid rod on the fruit-peduncle-branch system.

For Routine 2 the experiment was conducted in a completely randomized design for samples with unripe fruits, with three replicates, considering the following factors: four frequencies $(20,30,40$ and $50 \mathrm{~Hz})$, three amplitudes $(0.002$, 0.003 and $0.004 \mathrm{~m}$ ) and two forms to vibration transmission (with and without a direct impact on the fruit-pedunclebranch system). Finally, Routine 3 presented the same design of Routine 2, however, it was analyzed for fruits in ripe conditions.

The detachment efficiency data, obtained from testing of the different experimental routines, were first analyzed by the Shapiro-Wilk normality test at the 5\% significance level. For data with a normal distribution, analyses of variance were performed considering a significance level of 5\%. The means for the qualitative factors were evaluated using Tukey's test at the 5\% significance level. The means for the quantitative factors were evaluated using regression analysis in which 
the models were selected according to the significance of the coefficients and the coefficient of determination.

For data not normally distributed, a nonparametric analysis was used. First, the Kruskal-Wallis test was performed. For application of the nonparametric tests, organization of the data was necessary so that the factors used in the analysis were organized into treatments for multiple comparison using the Dunn's test at the $10 \%$ significance level.

\section{RESULTS}

For Routine 1 (vibrations transmitted with direct impact to the fruit-peduncle-coffee branch system), the Table 1 shows the results of the analysis of variance, with the ripening and frequency factors exhibiting significant differences at the 5\% level. Similar results involving such factors were found in the literature (Santos et al., 2010a; Santinato et al., 2014; Coelho et al., 2015; Ferreira Júnior et al., 2018; Silva et al., 2015).

Table 1: Results of the analysis of variance for the experimental arrangement with direct impact on the coffee fruit-pedunclebranch system.

\begin{tabular}{cccccc}
\hline SV & DF & SQ & MS & F & p-value \\
\hline Ripening (R) & 1 & $1,921.04$ & $1,921.04$ & $10.07^{*}$ & 0.00 \\
Frequency (F) & 3 & $19,704.51$ & $6,568.17$ & $34.43^{*}$ & 0.00 \\
Amplitude (A) & 2 & $16,794.13$ & $8,397.06$ & $44.02^{*}$ & 0.00 \\
R x F & 3 & 408.39 & 136.13 & 0.71 & 0.54 \\
R x A & 2 & $1,855.06$ & 927.53 & $4.86^{*}$ & 0.01 \\
F x A & 6 & $5,059.62$ & 843.27 & $4.42^{*}$ & 0.00 \\
R x F x A & 6 & $1,155.74$ & 192.62 & 1.01 & 0.43 \\
Residue & 48 & $9,156.44$ & 190.76 & & \\
Total & 71 & $56,054.94$ & 789.51 & & \\
\hline
\end{tabular}

* significant at the $5 \%$ level; SV: source of variation; DF: degrees of freedom; SQ: sum of squares; MS: mean square.

When the average detachment efficiency obtained in the experimental arrangement from the impact was analyzed, the detachment efficiency for the ripe fruit was $41.98 \%$, whereas the average detachment efficiency for the unripe fruit was $31,65 \%$.

Significant differences were observed for the frequency factor, a result also found by other authors (Santos et al., 2010a; Santos et al., 2010b; Coelho et al., 2015). The results showed detachment efficiencies of $14.51 \%, 28.31 \%$, $47.11 \%$ and $57.34 \%$ for frequencies of $20,30,40$, and 50 $\mathrm{Hz}$, respectively. Equation 2 represents the model determined to describe the detachment efficiency as a function of the vibration frequency of the rods, and Figure 4 represents it graphically.
$E f=1.47 F-14.7$

$$
\left(\mathrm{R}^{2}=98.8 \%\right)
$$

where:

$E f=$ the unripe fruit detachment efficiency (\%); and

$F=$ the vibration frequency of the rods $(\mathrm{Hz})$.

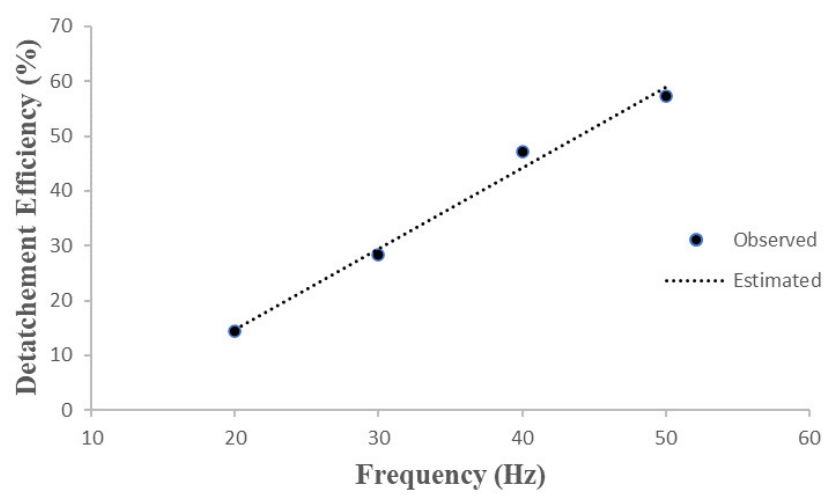

Figure 4: Linear model that describes the detachment efficiency as a function of vibration frequency.

Again, through regression analysis, a model was constructed to describe the detachment efficiency as a function of the vibration amplitude of the rods for the unripe ripening stage. Equation 3 represents this model, and Figure 5 represents it graphically.

$E f=18611 A-19.01 \quad\left(\mathrm{R}^{2}=98.94 \%\right)$.

where:

$E f=$ the unripe fruit detachment efficiency (\%); and

$A=$ the vibration amplitude of the rods (m).

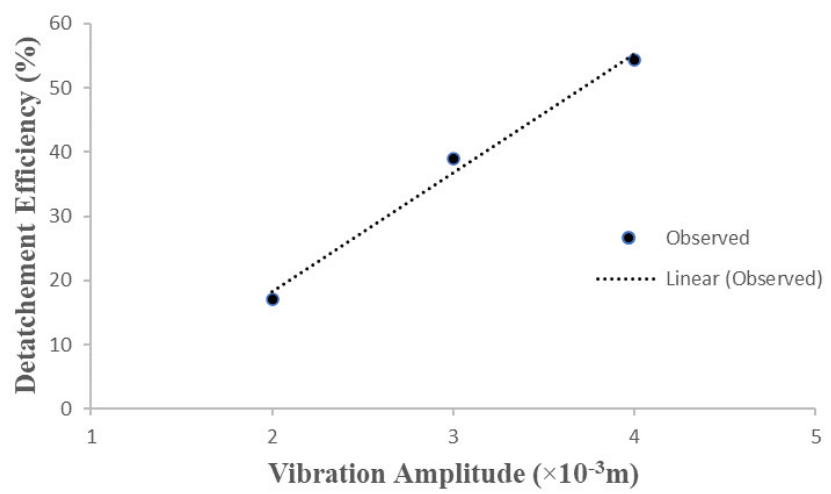

Figure 5: Linear model to describe the detachment efficiency as a function of vibration amplitude.

The evaluation of fruit detachment efficiency as a function of ripening stage and vibration amplitude was performed by breaking down the interaction of ripening within the amplitude levels (Table 2).

For the amplitude of $0.002 \mathrm{~m}$, no significant difference was found for the detachment efficiency between the ripening 
stages. For amplitudes of 0.003 and $0.004 \mathrm{~m}$, the detachment efficiency was higher for the ripe stage (Table 3 ).

Table 2: Results of the analysis of variance of the breakdown of the interaction of the ripening factor within the amplitude levels.

\begin{tabular}{cccccc}
\hline SV & DF & SQ & MS & F & p-value \\
\hline Ripening: $0.002 \mathrm{~m}$ & 1 & 54.92 & 54.92 & 0.29 & 0.59 \\
Ripening: $0.003 \mathrm{~m}$ & 1 & 929.75 & 929.75 & $4.87^{*}$ & 0.03 \\
Ripening: $0.004 \mathrm{~m}$ & 1 & $2,791.43$ & $2,791.43$ & $14.63^{*}$ & 0.00 \\
$\quad$ Residue & 48 & $9,156.44$ & 190.76 & &
\end{tabular}

* significant at the $5 \%$ level; SV.: source of variation; DF.: degrees of freedom; SQ.: sum of squares; MS.: mean square.

Table 3: Average detachment efficiency (\%) as a function of the ripening stage and vibration amplitude.

\begin{tabular}{cccc}
\hline \multirow{2}{*}{ Ripening stage } & \multicolumn{3}{c}{ Amplitude } \\
\cline { 2 - 4 } & $0.002 \mathrm{~m}$ & $0.003 \mathrm{~m}$ & $0.004 \mathrm{~m}$ \\
\hline Unripe & $18.64 \mathrm{a}$ & $32.75 \mathrm{a}$ & $43.56 \mathrm{a}$ \\
Ripe & $15.62 \mathrm{a}$ & $45.21 \mathrm{~b}$ & $65.13 \mathrm{~b}$ \\
\hline
\end{tabular}

Different letters in the columns indicate significant differences in the means by Tukey's test at the $5 \%$ level.

When breaking down the amplitude factor within the ripening stages (Table 4), the interactions between the factors were significant for both ripening stages. Therefore, the detachment efficiency was influenced by the vibration amplitude for the unripe and ripe ripening stages.

Table 4: Results of the analysis of variance of the breakdown of the interaction of the amplitude factor within the ripening stages.

\begin{tabular}{cccccc}
\hline SV & DF & SQ & MS & F & p-value \\
\hline Unripe: Amp & 2 & $3,749.34$ & $1,874.67$ & $9.83^{*}$ & 0.00 \\
Ripe: Amp & 2 & $14,899.85$ & $7,449.92$ & $39.05^{*}$ & 0.00 \\
Residue & 48 & $9,156.44$ & 190.76 & & \\
\hline
\end{tabular}

* significant at the $5 \%$ level; SV.: source of variation; DF.: degrees of freedom; SQ.: sum of squares; MS.: mean square.

Regression analysis was used to determine a model for describing the detachment efficiency as a function of the amplitude of the rods for the unripe and ripe ripening stages.

Equations $4\left(\mathrm{R}^{2}=99.44 \% / \mathrm{S}\right.$. error $=1.36 / \mathrm{p}$. value $=0.04)$ and $5\left(\mathrm{R}^{2}=98.74 \% / \mathrm{S}\right.$. error $=3.95 / \mathrm{p}$. value $=$ 0.07 ) represent the model chosen to describe the detachment efficiency as a function of the amplitude for the unripe and ripe stages, respectively. Figure 6 provides a graphic representation of the chosen models.

$E f=12460 A-5.74$
$E f=24760 A-32.29$

where:

$E f=$ the unripe fruit detachment efficiency (\%); and $A=$ the vibration amplitude of the rods (m).

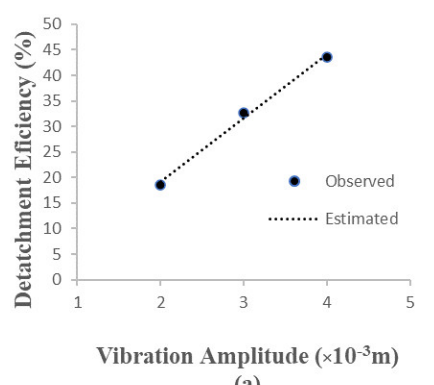

(a)

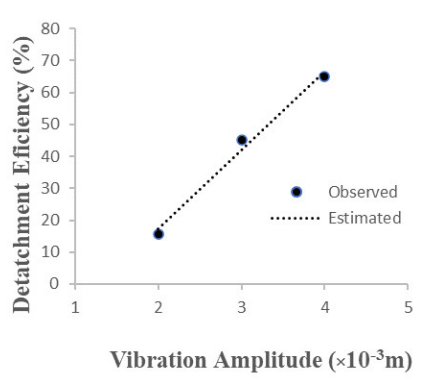

(b)
Figure 6: Linear model that describes the detachment efficiency as a function of vibration amplitude for unripe (a) and ripe (b) fruits.

The breakdown of the frequency factor within the amplitude levels was also studied in the analysis of variance (Table 5). Only the interaction between frequency and an amplitude of $0.002 \mathrm{~m}$ was not significant at the $5 \%$ level.

Table 5: Results of the analysis of variance of the breakdown of the interaction of the frequency factor within the amplitude levels.

\begin{tabular}{cccccc}
\hline SV & DF & SQ & MS & F & p-value \\
\hline Freq: $0.002 \mathrm{~m}$ & 3 & $1,253.10$ & $4,177.00$ & 2.19 & 0.10 \\
Freq: $0.003 \mathrm{~m}$ & 3 & $6,979.85$ & $23,266.15$ & $12.20^{*}$ & 0.00 \\
Freq: $0.004 \mathrm{~m}$ & 3 & $16,531.18$ & $5,510.39$ & $28.89 *$ & 0.00 \\
$\quad$ Residue & 48 & $9,156.44$ & 190.76 & &
\end{tabular}

* significant at the $5 \%$ level.; SV.: source of variation; DF.: degrees of freedom; SQ.: sum of squares; MS.: mean square.

Although the interaction between the frequency and the amplitude of $0.002 \mathrm{~m}$ was not significant, a tendency existed for the average detachment efficiency to increase as the frequency increased. Detachment efficiencies of $7.25 \%$, $14.86 \%, 19.15 \%$, and $27.23 \%$ were obtained for frequencies of $20,30,40$, and $50 \mathrm{~Hz}$, respectively.

Equations $6\left(\mathrm{R}^{2}=98.65 \%\right.$; $\mathrm{S}$. error $=2.81$ and $\mathrm{p}$. value $=0.01)$ and $7\left(R^{2}=92.42 \% /\right.$ S. error $=10.22 / \mathrm{p}$. value $\left.=0.04\right)$ represent models that describe the detachment efficiency as a function of frequency and amplitudes of 0.003 and $0.004 \mathrm{~m}$, respectively. The selected models are graphically represented in Figure 7.

$E f=1.51 F-14.03$

$E f=2.25 F-24.63$ 
where:

$E f=$ the detachment efficiency (\%); and

$F=$ the vibration frequency $(\mathrm{Hz})$.
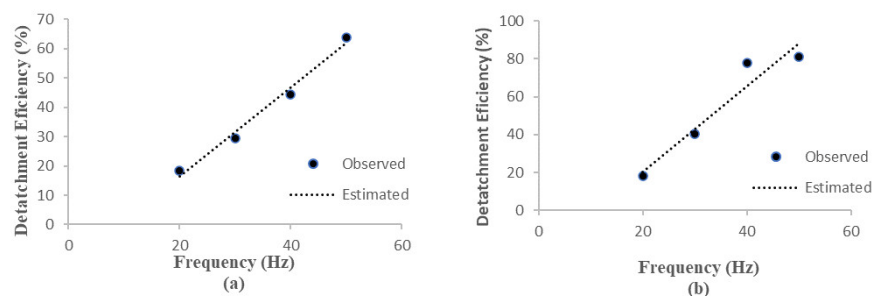

Figure 7: Linear model that describes the detachment efficiency as a function of the frequency for an amplitude of 0.003 (a) and $0.004 \mathrm{~m} \mathrm{(b)}$.

The data for Routine 2 (comparison between the different forms of transmission of vibration to the unripe fruits) were analyzed by the Shapiro-Wilk normality test at the $5 \%$ level and were not normally distributed; therefore, the nonparametric Kruskal-Wallis test was applied. At least one combination of the factors that composed the treatments evaluated had different means between them with a statistical significance at the 5\% level. Table 6 shows the evaluated treatments, which were composed of the combination of factors considered in Routine 2.

Dunn's test was applied to determine which combinations of treatments have means different at the $10 \%$ significance level. Some contrasts of treatments with significant differences according to Dunn's test are shown in Figure 8.

In Routine 3 (comparing different forms of vibration transmission in ripe fruits), the Shapiro-Wilk normality test was applied at the 5\% level, and the data again showed no normal distribution. The nonparametric Kruskal-Wallis test was then applied, at a 5\% significance level, and at least one of the comparisons between treatments had significantly different means.

The Dunn's test determined which comparisons between treatments had significantly different means at the $10 \%$ level. The organization of these treatments follows the same order shown in Table 6. Figure 9 shows some combinations of the Dunn's test that were significant and should be discussed.

\section{DISCUSSION}

From the results of Routine 1, the ripening factor was significant at the $5 \%$ level (Table 1 ). This result agrees with those results found in the literature when only the effect of mechanical vibrations on detachment efficiency was evaluated (Santos et al., 2010a; Santos et al., 2010b; Coelho et al., 2015). In this context, one can infer that a selective harvesting process is achievable when using the impact of the rods to transmit vibration to the coffee fruits (Ferreira Júnior et al., 2018). Silva et al. (2015) evaluated the performance of a KTR harvester configured to operate at different vibration frequencies of the rods and obtained low average detachment efficiency for the green fruits, approximately $6.8 \%$, despite of coffee plants presenting $31.0 \%$ of fruits at this ripening stage. These result confirm that selective coffee harvesting by using mechanical vibrations is achievable.

Table 6: Arrangement of the treatments composed by the combination of the factors evaluated.

\begin{tabular}{|c|c|c|c|}
\hline Treatment & $\begin{array}{c}\text { Impact on the } \\
\text { fruit }\end{array}$ & $\begin{array}{l}\text { Frequency } \\
(\mathrm{Hz})\end{array}$ & $\begin{array}{l}\text { Amplitude } \\
\left(\times 10^{-3} \mathrm{~m}\right)\end{array}$ \\
\hline 1 & No & 20 & 2 \\
\hline 2 & No & 20 & 3 \\
\hline 3 & No & 20 & 4 \\
\hline 4 & No & 30 & 2 \\
\hline 5 & No & 30 & 3 \\
\hline 6 & No & 30 & 4 \\
\hline 7 & No & 40 & 2 \\
\hline 8 & No & 40 & 3 \\
\hline 9 & No & 40 & 4 \\
\hline 10 & No & 50 & 2 \\
\hline 11 & No & 50 & 3 \\
\hline 12 & No & 50 & 4 \\
\hline 13 & Yes & 20 & 2 \\
\hline 14 & Yes & 20 & 3 \\
\hline 15 & Yes & 20 & 4 \\
\hline 16 & Yes & 30 & 2 \\
\hline 17 & Yes & 30 & 3 \\
\hline 18 & Yes & 30 & 4 \\
\hline 19 & Yes & 40 & 2 \\
\hline 20 & Yes & 40 & 3 \\
\hline 21 & Yes & 40 & 4 \\
\hline 22 & Yes & 50 & 2 \\
\hline 23 & Yes & 50 & 3 \\
\hline 24 & Yes & 50 & 4 \\
\hline
\end{tabular}

Silva et al. (2010) studied the axial force of detachment of the coffee fruit from the peduncle. In some cases, the necessary force for detachment was $73.42 \%$ higher for the unripe fruit than for the ripe fruit. This result can be attributed to the greater stiffness of the peduncles of the unripe fruits. Tinoco and Peña (2018) also observed a reduction on modulus of elasticity due the advance of the coffee ripening stage. According to Rodrigues and Ono (2001), the decrease in stiffness is related to the degradation of the peduncle cell walls by enzymatic activity. However, when transmitting vibration by direct impact to the fruit, energy is rapidly and abruptly transmitted, resulting in similar detachment efficiencies for unripe and ripe fruits (Figure 3). 


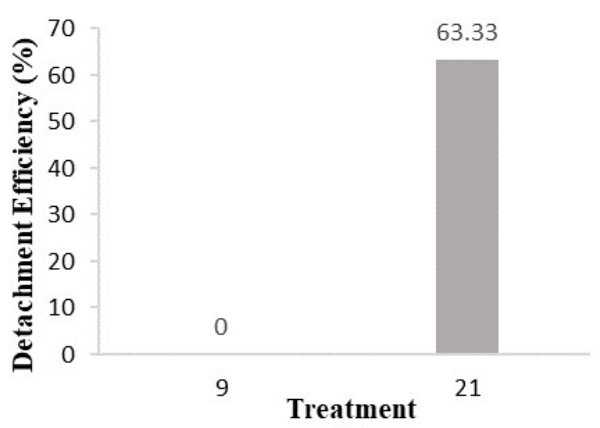

(a)

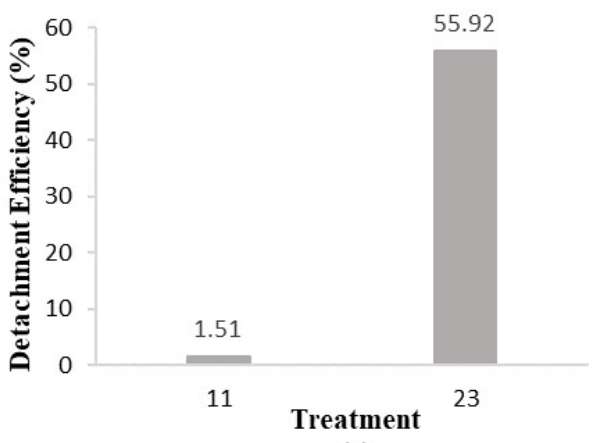

(c)

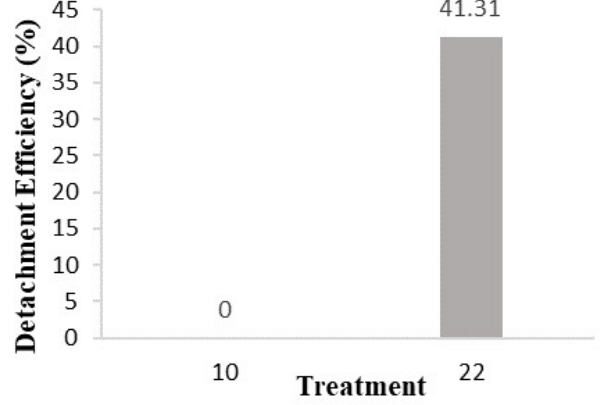

(b)

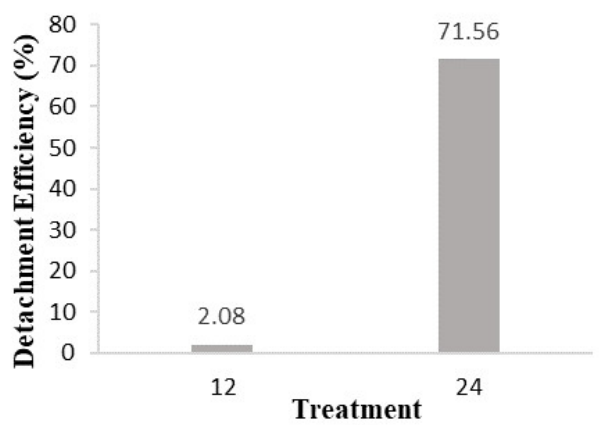

(d)

Figure 8: Average detachment efficiency obtained by comparing the respective treatments, (a): 9 and 21 ; (b): 10 and $22 ;$ (c): 11 and 23; (d): 12 and 24.

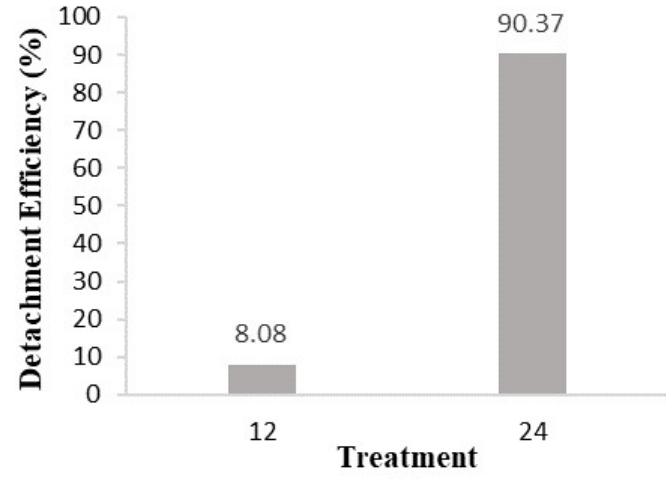

(a)

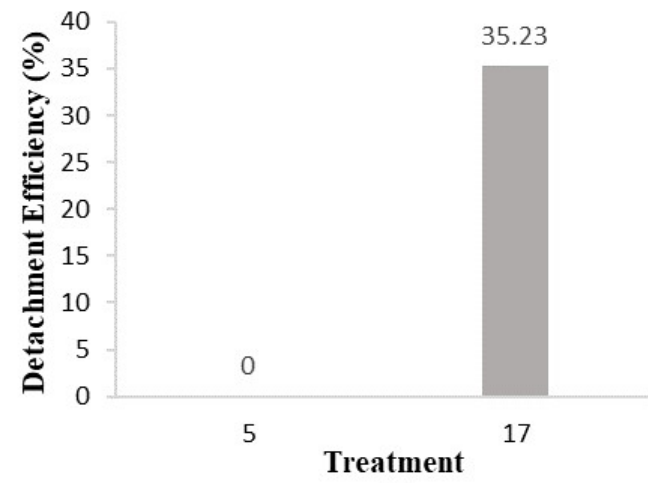

(b)

Figure 9: Average detachment efficiency obtained by treatments 12 and 24 (a) and average detachment efficiency obtained by treatments 5 and 17 (b).

The increase in the frequency imposed on a vibrating system with fixed amplitude results in an increase in the accelerations to which this system is subjected. Greater accelerations in turn increase the energy delivered to the sample, thus ensuring a greater number of detached fruits. Santos et al. (2010a) state that the vibration frequency and amplitude are directly related to the detachment efficiency.

The vibration amplitude that the rods were subjected to also had a significant effect on the detachment efficiency. This result corroborates the findings of other authors (Santos et al., 2010a; Coelho et al., 2015). The analysis of the average values shows an increase in the detachment efficiency as the vibration amplitude of the rods increases. For values of 0.002 ,
0.003 , and $0.004 \mathrm{~m}$, an average detachment efficiency was observed of $17.12 \% ; 38.98 \%$, and $54.35 \%$, respectively. This behavior may be attributed to the increase in vibration energy with increasing amplitude.

Considering the means that differ from each other, a lower fruit detachment efficiency is observed at the unripe stage. Silva et al. (2010) studied the coffee fruit detachment force and conclude that fruits in unripe maturation stage need greater forces to be harvested. This behavior may again be associated with the reduced stiffness of the peduncle in the ripe coffee samples (Coelho et al., 2015; Tinoco and Peña, 2018).

Equations 4 and 5 show that, regardless of the vibration frequency to which the samples were subjected in the 
experiment, an increase occurred in the detachment efficiency for the unripe and ripe fruits with the increase in the amplitude of fiber glass rigid rods.

Increased detachment efficiency was observed as the vibration frequency and amplitude of the rigid rods increased. These results corroborate studies found in the literature (Santos et al., 2010a; Santos et al., 2010b; Coelho et al., 2015; Villibor et al., 2019). By increasing any of the two factors, either alone or in combination, the acceleration to which the sample is subjected increases accordingly. Higher accelerations indicate that more energy was transmitted and, consequently, more fruits will be harvested.

The average detachment efficiency reached values greater than $80 \%$, i.e., the amount of vibrational energy supplied to the samples was sufficient for efficient detachment of the fruits. Using the highest frequencies and amplitudes, obtaining satisfactory results is possible when performing harvest with a single pass. Santos et al. (2010a) obtained an average detachment efficiency of $65.25 \%$ for a frequency of $26.67 \mathrm{~Hz}$ and amplitude of $0.0075 \mathrm{~m}$. Importantly, in this study, the authors only studied the effect of vibration on fruits without the impact of the rods. Therefore, the results obtained in Routine 1 indicate that, for a more efficient harvest, the vibration should be transmitted from the impact of the rods on the fruits, which validates the principle already used in harvesters.

For the results of Routine 2, the treatment configurations in which the fruits were subjected to the impact of the rigid rod obtained higher average detachment efficiency compared to those without impact of the rod on the fruit (Figure 8). The importance of using impact in combination with mechanical vibration to obtain higher coffee fruit detachment efficiency is apparent. The comparison between treatment 12 and treatment 24 indicated a difference of $69.48 \%$, which reveals that vibration in combination with impact can be up to $70 \%$ more efficient for detaching unripe coffee fruits when compared to the use of only the vibration.

This behavior was also observed by Gomes, Santos and Jesus (2017) considering a simple scenario, where the detachment efficiency by combination of impact was evaluated for isolated fruits. The authors also concluded that mechanical vibrations in association with impact presented a higher detachment efficiency of coffee fruits when compared with the detachment performed only by mechanical vibrations.

The impact is characterized by the transmission of the kinetic energy from the rigid rods in a short period of time, thus providing higher-intensity accelerations to the coffee fruits. Greater accelerations indicate a greater amount of energy delivered to the fruit.

The average detachment efficiency of the treatments was significant. If we compare treatment 21 with treatment 24 , an increase of $8.21 \%$ occurred in the detachment efficiency.
The only variable that differs among these treatments is frequency; thus, the observed difference can be attributed to the difference in frequency. This behavior was also found in the literature (Santos et al., 2010a; Santos et al., 2010b; Coelho et al., 2015), and it may be explained by the greater energy delivered to samples with increasing frequency.

Regarding selective harvesting, the use of vibration without the impact of the rods would be a solution to achieve this goal. The detachment efficiency obtained in this analysis (vibration without impact) was low, indicating that fruits at the unripe ripening stage would not be effectively harvested if excited at the frequency and amplitude levels used.

In Routine 3, the results presented in Figure 9 show the importance of harvesting coffee with a combination of mechanical vibration and impact. Treatments 12 and 24 (Figure 9a) are characterized by a frequency of $50 \mathrm{~Hz}$ and an amplitude of $0.004 \mathrm{~m}$. However, when considering the effect of the impact, the detachment efficiency is $90.37 \%, 11$ times higher than the efficiency obtained only through the action of vibration. Similar behavior was observed in the comparison between treatments 5 and 17 , characterized by a frequency of $30 \mathrm{~Hz}$ and amplitude of $0.003 \mathrm{~m}$, in which the observed performance efficiencies were $35.23 \%$ and $0.0 \%$ for vibration with and without impact on the fruit-peduncle-branch system, respectively.

According Gomes et al. (2017), the detachment efficiency using mechanical vibrations in association with impact was $19.4 \%$ higher when compared to tests performed using only mechanical vibrations. The authors evaluated a simple scenario, composed by cases involving isolated fruits, which does not represent an actual coffee harvesting process.

In this study, it was used samples of coffee branches containing a set of fruits (Figure 2), which is a scenario more representative of coffee harvesting process by mechanical vibrations.

Notably, high detachment efficiency was observed when vibration was used in combination with impact because, even for a small time interval, the vast majority of the fruits were subjected to an excitation with minimum dissipation of energy. When the vibration is transmitted through the clamping of the branch with the vibrating machine, part of the energy supplied to the sample dissipates because of the cushioning of the branch and, consequently, the vibration did not reach a sufficient magnitude to promote fruit detachment.

However, the impact of the rigid rods in combination with vibration can also increase the damage to the fruits and to the coffee plant. Damage to the fruits may cause decreased coffee quality and, consequently, a lower sale price. Damage to the coffee plant can cause yield losses in the next harvest (Sakiyama et al., 2015).

Ensuring that the vibrating rods of a detachment machine come into contact with all fruits in a coffee plant is 
not a simple task with regard to machine designs. Many design difficulties exist, from the mechanical construction materials required to the variability in the shape and size of coffee plants. However, with this study, the importance of this fruitrod interaction during the harvesting process by mechanical vibrations is clarified.

\section{CONCLUSIONS}

The following conclusions can be drawn under the analyzed conditions:

- Detachment efficiency increases as the ripening stage progresses from unripe to ripe.

- A higher detachment efficiency can be observed as the vibration frequency and amplitude are increased because greater vibrational energy is imposed on the fruit.

- In a vibration process without impact on the fruits, the detachment efficiency was low, indicating that the frequency and amplitude levels evaluated in this study are not adequate for an efficient harvest without the use of impact.

- When using the impact of rods in combination with vibration, the average detachment efficiency reached $90 \%$.

- The detachment efficiency of a process that combines vibration and impact of the rods is up to 11 times greater than a process without the impact of vibrating rods.

- An improvement in the detachment efficiency could be obtained by ensuring that the rods impact the fruits during the coffee harvesting process.

\section{ACKNOWLEDGMENTS}

The authors thank the Fundação de Amparo à Pesquisa do Estado de Minas Gerais (Fapemig), Conselho Nacional de Desenvolvimento Científico e Tecnológico (CNPq) and Coordenação de Aperfeiçoamento de Pessoal de Nível Superior (Capes), for financial support.

\section{REFERENCES}

CIRO, H. J. Coffee harvesting I: Determination of the natural frequencies of the fruit stem system in coffee tress.

Applied Engineering in Agriculture, 17(4):475-479, 2001.

COELHO, A. L. F. et al. Dynamic behavior of the coffee fruit-stem-branch system using stochastic finite element method. Coffee Science, 11(1):1-11, 2016.

COELHO, A. L. F. et al. Detachment efficiency of fruits from coffee plants subjected to mechanical vibrations. Pesquisa Agropecuária Tropical, 45(1):406-412, 2015.
COMPANHIA NACIONAL DE ABASTECIMENTO CONAB. Acompanhamento da safra brasileira: Café V.4 - Safra 2019 - N.1 - Primeiro levantamento, janeiro/ 2019. Available in: <http://www.conab.gov.br/>. Access in: January, 27, 2019.

CUNHA, J. P. B. et al.Viabilidade técnica e econômica de diferentes sistemas de colheita do café. Coffee Science, 11(3):416-425, 2016.

FERREIRA JÚNIOR, L. G. et al. Characterization of the coffee fruit detachment force in crop subjected to mechanized harvesting. Coffee Science, 13(1):71-79. 2018.

FERREIRA JUNIOR, L. G. et al. Recomendação para colheita mecânica do café baseado no comportamento de vibração das hastes derriçadoras. Ciência Rural, 46(2):16,2015 .

GOMES, E. Q.; SANTOS, F. L.; JESUS, V. A. M. Influence of the impact of a rigid rod on the coffee fruits detachment by mechanical vibrations. Agrarian, 9(1):172-181, 2017.

LANNA, G. B. M.; REIS, R. P. Influência da mecanização da colheita na viabilidade econômico-financeira da cafeicultura no sul de minas gerais. Coffee Science, 7(2):110-121, 2012.

OLIVEIRA, E. et al. Influência da vibração das hastes e da velocidade de Deslocamento da colhedora no processo de colheita mecanizada do café. Revista Engenharia Agrícola, 27(3):714-721, 2007.

ORTEGA, A. C.; JESUS, C. M. Território café do Cerrado: Transformações na estrutura produtiva e seus impactos sobre o pessoal ocupado. Revista Economia Sociologia Rural, 49(3):771-800, 2011.

RODRIGUES, J. D.; ONO, E. O. Na hora certa. Cultivar: Grandes Culturas, 30(1):32-34, 2001.

SAKIYAMA N. S. et al. Café arábica do Plantio à Colheita. 1. ed. Viçosa - MG: UFV. v. 1. 2015. 316p.

SANTINATO, F. et al. Análise quali-quantitativa da operação de colheita mecanizada de café em duas safras. Coffee Science, 9(4):495-505, 2014.

SANTOS, F. L. et al. Analysis of the coffee harvesting process using an electromagnetic shaker. Acta Scientiarum Agronomy, 32(3):373-378, 2010a.

SANTOS, F. L. et al. Efeito da frequência e amplitude de vibração sobre a derriça de frutos de café. Revista Brasileira de Engenharia Agrícola e Ambiental, 14(1):425-431, $2010 \mathrm{~b}$. 
SANTOS, F. L. et al. Simulation of the dynamic behavior of the coffee fruit-stem system using finite element method. Acta Scientiarum Technology, 37(1):11-17, 2015 .

SESSIZ, A.; OZCAN, M. T. Olive removal with pneumatic branch shaker and abscission chemical. Journal of Food Engineering, 76(2):148-153, 2006.

SILVA, E. P.; SILVA, F. M.; MAGALHÃES, R. R. Application of finite elements method for structural analysis in a coffee harvester. Engineering, 6(1):138-147, 2014.

SILVA, F. C. et al. Comportamento da força de desprendimento dos frutos de cafeeiros ao longo do período de colheita. Ciência e Agrotecnologia, 34(2):468-474, 2010.

SILVA, F. C. et al. Efficiency of coffee mechanical and selective harvesting in different vibration during harvest time. Coffee Science, 10(1):56-64, 2015.

TINOCO, H. A.; PEÑA, F. M. Harmonic stress analysis on Coffea arábica L. Var. Colombia fruits in order to simulate the selective detachment: A finite element analysis. Simulation, 94(2):163-174, 2018.

VILLIBOR, G. P. et al. Dynamic behavior of coffee fruit-stem system using modeling of flexible bodies. Computers and Electronics in Agriculture, 166(1):105009, 2019. 